\title{
Horizontal-guided Bone Regeneration using a Titanium Mesh and an Equine Bone Graft
}

\author{
${ }^{1}$ Danilo Alessio Di Stefano, ${ }^{2}$ Gian Battista Greco, ${ }^{3}$ Lorenzo Cinci, ${ }^{4}$ Laura Pieri
}

\begin{abstract}
Aim: The present work describes a horizontal ridge augmentation in which a titanium mesh was preshaped by adapting it to a stereolithographic model of the patient's jaw that was fabricated from CT scans.
\end{abstract}

Background: Guided bone regeneration (GBR) involves covering the augmentation site with a long-lasting barrier to protect it from the invasion of surrounding soft tissues. Among barriers, titanium meshes may provide a successful outcome, but the intraoperatory time needed to shape them is a disadvantage.

Case description: The 54-year-old patient, missing the right mandibular second bicuspid, first molar, and second molar, had her atrophic ridge augmented with a 30:70 mixture of autogenous bone and equine, enzyme-deantigenic collagenpreserved bone substitute. Two conical implants were inserted concomitantly in the second bicuspid and first molar positions, and the site was protected with the preshaped mesh. Four months later, the titanium mesh was retrieved, a bone sample was collected, and histological and histomorphometric analyses were performed. Provisional and definitive prostheses were then delivered, and follow-up controls were performed for up to 24 months.

Conclusion: Preshaping the mesh on a model of the patient's mandible shortened the surgical time and enabled faster mesh placement. Two years after surgery, the implants were perfectly functional, and the bone width was stable over time as shown by radiographic controls. Histological analysis of the bone sample showed the heterologous biomaterial to be biocompatible and undergoing advanced remodeling and replacement with newly formed bone.

Clinical significance: Preshaping a titanium mesh over a stereolithographic model of the patient's jaw allowed for a significant reduction of the intraoperative time and may be therefore, advisable in routine practice.

${ }^{1}$ Department of Dentistry, Vita e Salute San Raffaele University Milan, Italy

${ }^{2}$ Private Practice, Trezzano sul Naviglio, Milan, Italy

${ }^{3}$ Department of Neuroscience, Psychology, Drug Research and Child Health (Neurofarba), Pharmacology and Toxicology Section, University of Florence, Florence, Italy

${ }^{4}$ Department of Health Sciences, Interdepartmental Forensic Medicine Section, University of Florence, Florence, Italy

Corresponding Author: Danilo Alessio Di Stefano, Professor Department of Dentistry, Vita e Salute San Raffaele University Milan, Italy, Phone: 390248705703, e-mail: distefano@ centrocivitali.it
Keywords: Case report, Guided bone regeneration, Horizontal bone augmentation, Titanium mesh, Xenografts.

How to cite this article: Di Stefano DA, Greco GB, Cinci L, Pieri L. Horizontal-guided Bone Regeneration using a Titanium Mesh and an Equine Bone Graft. J Contemp Dent Pract 2015;16(2):154-162.

\section{Source of support: Nil}

Conflict of interest: None

\section{INTRODUCTION}

Prosthetic-driven implantology requires planning the patient rehabilitation in advance, designing the optimal patient's functional and esthetic rehabilitation with specialized software programs, determining where implants will be placed. Though, patients requesting prosthetic rehabilitation usually have partially or even totally atrophic bone ridges ${ }^{1,2}$ calling for bone augmentation to allow placing implants in accordance to the predefined rehabilitation plan. Vertical or horizontal ridge augmentation techniques include bone distraction, inlay and onlay bone grafting, inferior alveolar nerve transposition, and guided bone regeneration (GBR) techniques. ${ }^{3}$

The GBR procedure requires a barrier to be interposed between the regenerating site and the surrounding soft tissues. ${ }^{4-5}$ This prevents fast-duplicating connective and epithelial cells from colonizing the regenerating site, facilitating site colonization by osteoprogenitor cells. Barriers must be able to block soft tissue cells and, at the same time, display a certain rigidity to avoid collapsing into the volume they are protecting. Rigid or semi-rigid barriers also isolate the regenerating site from mechanical stresses that could disturb the first pro-osteogenic events.

Many barriers have been extensively studied, including membranes made of polytetrafluoroethylene (PTFE); expanded PTFE (ePTFE); collagen; poly (lactic acid), poly (glycolic acid), and their copolymers; and titanium meshes. ${ }^{6-9}$ Titanium meshes have been used with success in clinical practice ${ }^{10-14}$ and display both advantages and disadvantages. ${ }^{15}$ They provide a thorough tenting effect, thanks to their rigidity and, being moldable, can be easily given the shape needed to cover the defect under treatment. Moreover, they maintain their shape over time. Yet they must be removed, are not resorbable, and require time-consuming shaping that is ordinarily performed after flap elevation in order to test the best fit of the mesh 
on the defect. This increases both the surgical time, and the risk of complications for the patient.

Titanium meshes have been used in conjunction with graft materials providing a more efficient scaffold than the blood clot to support cells and vessels. ${ }^{16,17}$ Autogenous bone has always been regarded as the gold standard for bone regeneration techniques, including GBR, since it provides progenitor and differentiated cells and growth factors. ${ }^{18}$ Its collection, though, always requires a second intra- or extra-oral surgical site exposing the patient to increased surgical risk and morbidity. Autogenous bone availability is limited, and often partial graft resorption is observed. ${ }^{19-21}$ Alternative materials have been subsequently tested, ranging from allogeneic bone to synthetic bone substitutes to xenografts.

Allogeneic bone availability, and its safe use, depend on proper tissue banking, ${ }^{22-24}$ and effective donor screening. ${ }^{25,26}$ Xenografts shows, theoretically, unlimited availability, and may represent an optimal alternative scaffold since bone tissue does not differ significantly among mammals as far as the mineral component composition and tridimensional structure are concerned. Bovine deproteinized bone has achieved satisfying results ${ }^{27-31}$ in the treatment of atrophic ridges and in conjunction with titanium meshes. ${ }^{16,17}$ However, although it shows good osteoconductive properties it still may have a low resorption capacity, ${ }^{32}$ possibly due to the high-temperature process it undergoes to virtually eliminate all its protein content. $^{33}$

An alternative xenograft is an enzyme-deantigenic form of equine bone. The enzymatic cleaning process preserves the type I bone collagen component in its native state, and this should enable improved bone regeneration, given the well-known biological properties of collagen. ${ }^{34-41}$ When osteoclasts were cultured over such equine bone substitutes, ${ }^{42}$ their adhesion and activity was significantly higher than that found for osteoclasts grown over deproteinized bovine bone. ${ }^{43}$ Moreover, sites augmented with equine bone alone or with a combination of equine and autogenous bone showed no differences as far as the expression of biochemical markers of bone regeneration was concerned. ${ }^{44}$ Enzymedeantigenic equine bone has already been used in clinical practice as a scaffold in bone regeneration of different bone defects ${ }^{45-49}$ and has been applied in orthopedic regenerative surgery. ${ }^{50}$

Digital modeling and three-dimensional (3D) printing of the arches based on CT or CBCT scans allows for creation of life-size models of the jaw under treatment. The following case report presents the use of the GBR technique to restore a horizontally atrophic lower jaw. A titanium grid was preshaped over a model of the defect and then sterilized. Two conical, root-form implants (the recommended choice for low-density bone sites) ${ }^{51,52}$ were placed, and the periimplant bone defect was filled with a mixture of autogenous bone and heterologous equinederived graft material. The site was then covered with the previously shaped titanium mesh.

\section{Case Description}

The patient was a nonsmoking 54-year-old woman with a non-contributory medical history who presented with a missing right mandibular second bicuspid and first and second molar (Fig. 1). She was seeking an implant-supported restoration to improve her masticatory function. Clinical and radiographic examination revealed a severe horizontal defect of the corresponding alveolar ridge (Figs 1 and 2). A treatment plan was developed calling for a GBR procedure and simultaneous placement of two dental implants. The patient provided informed consent.

On the basis of cone beam computed tomography (CBCT) scans, a model of the upper ridge was created (Fig. 3A) and used as a template to preshape a titanium mesh (Titanguide, Prodent Italia, Pero, Italy) some days

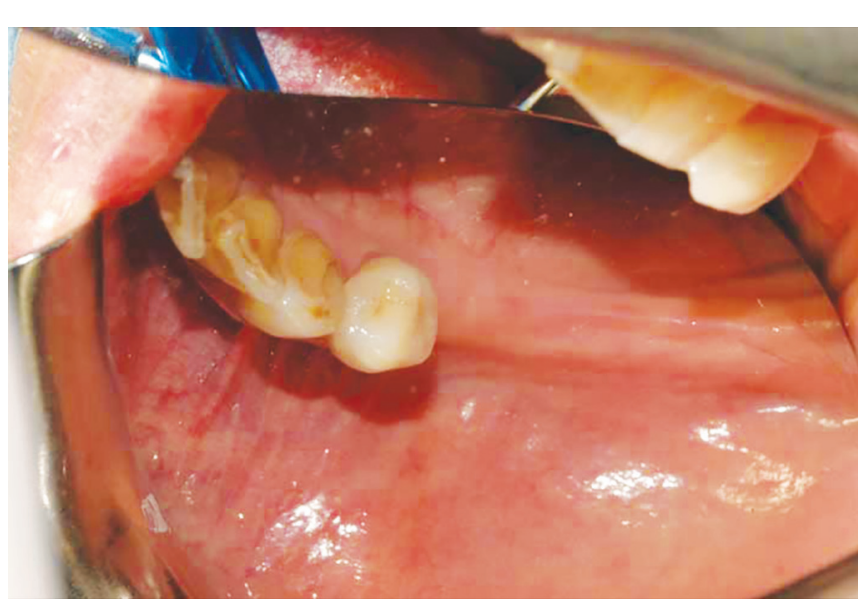

Fig. 1: Presurgical radiograph and intraoral appearance at clinical examination. The patient was missing her right mandibular second bicuspid, first molar, and second molar 


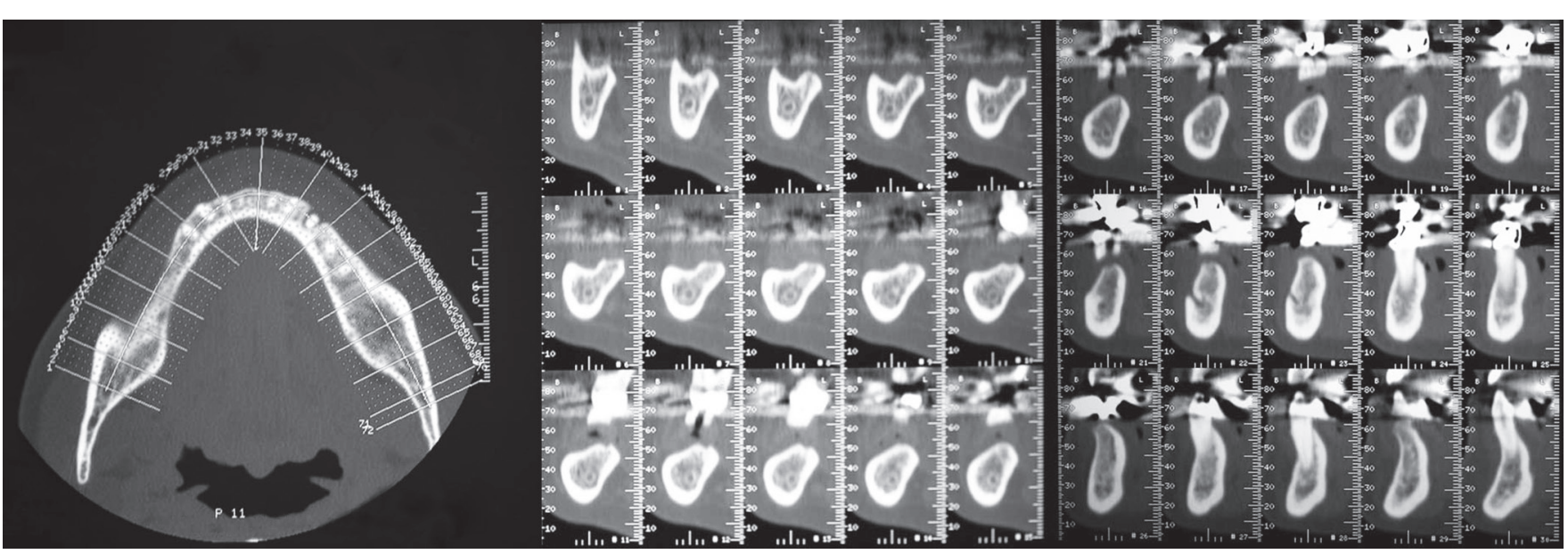

Fig. 2: Computed tomography scans showing the horizontal atrophy in the fourth quadrant
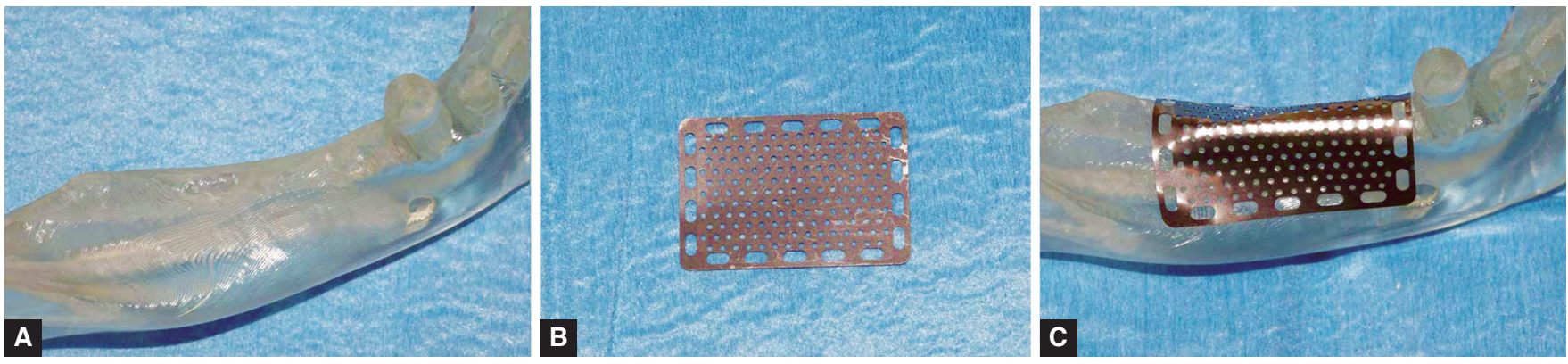

Figs $3 \mathrm{~A}$ to $\mathrm{C}$ : Stereolithographic model of the ridge and titanium mesh, before and after being shaped on the model

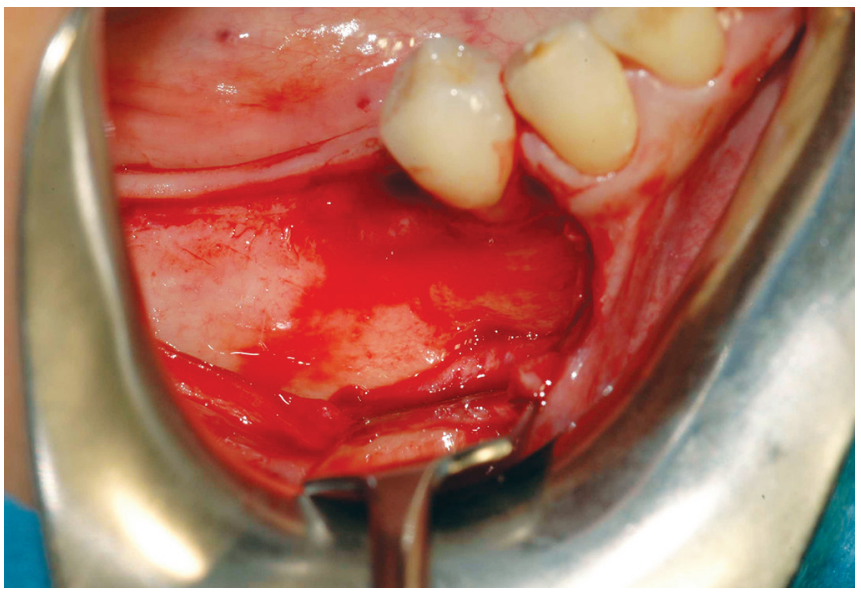

Fig. 4: A flap was prepared and elevated

before the date of surgery (Figs 3B and C). The titanium mesh was then sterilized in an autoclave.

Antibiotic prophylaxis (amoxicillin/clavulanic acid, Augmentin, Glaxo-SmithKline, Verona, Italy), 2 g, 1 hour before surgery and then every 12 hours for 7 to 9 days, was initiated and the patient was directed to rinse with chlorhexidine $0.2 \%$ (Corsodyl, Glaxo-SmithKline). Nimesulide (Aulin, Roche, Milano, Italy) $100 \mathrm{mg}$ also was administered, 1 hour before surgery and then twice a day for 5 days. Local anesthetic was administered by means of infiltration with $1 \%$ articaine with adrenaline 1:100000. A mid-crestal full-thickness incision was created within the keratinized mucosa of the edentulous ridge, extending it

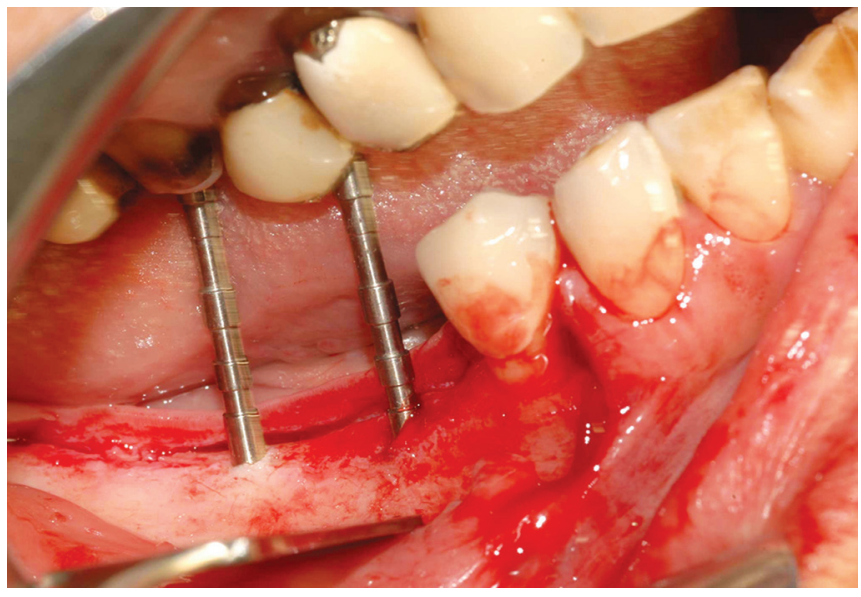

Fig. 5: Implant-like pins in position

to the first bicuspid through an intrasulcular incision and performing two vertical incisions to prepare a trapezoidal mucoperiosteal flap. The flap was then elevated to expose the right posterior sector of the mandible (Fig. 4).

Two conical osseointegrated implants, $4.2 \times 10 \mathrm{~mm}$, (Prime, Prodent Italia, Pero, Italy) were placed in the second bicuspid and first molar positions (Figs 5 and 6), and the fit of the shaped titanium mesh was checked on the ridge (Fig. 7). The site was then prepared for bone augmentation with a bone scraper (Safescraper ${ }^{\circledR}$ Twist, Meta, Reggio Emilia, Italy) to initiate bleeding and collect some autogenous bone. The autogenous bone was mixed with equine enzyme-deantigenated bone granules 


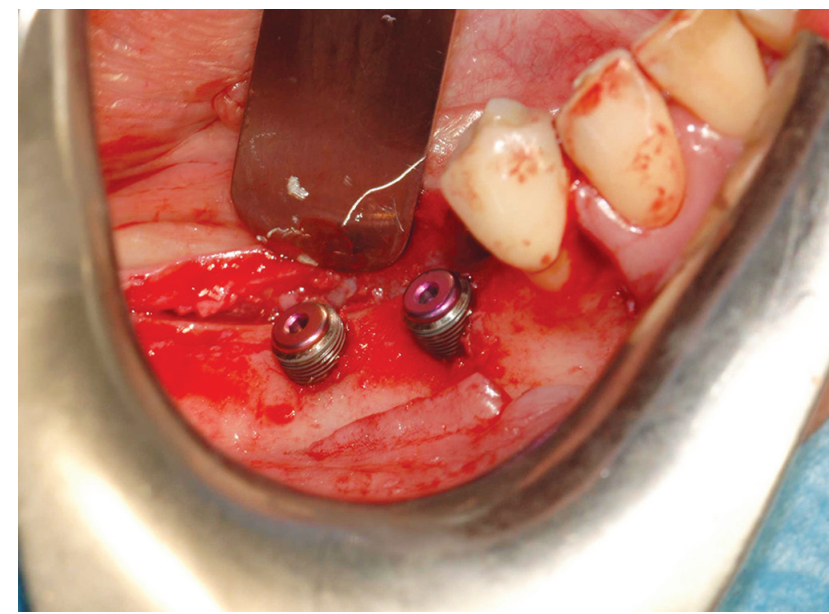

Fig. 6: Dental implants after placement with their respective cover screws

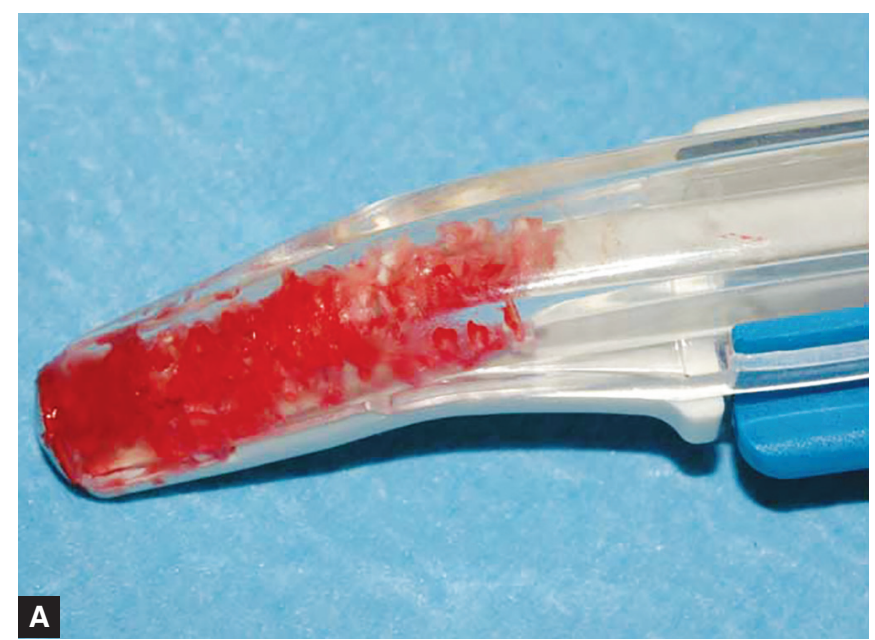

Figs 8A and B: Bone graft collection and preparation: autogenous bone is collected with a bone scraper (A) and mixed with the xenograft (B)
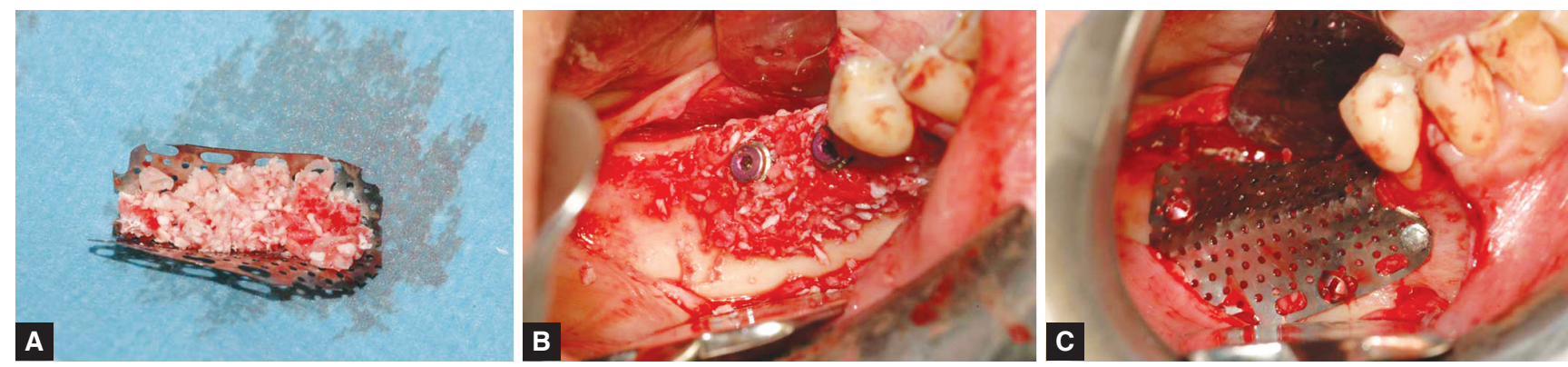

Figs 9A to C: Positioning of the mesh: the mesh is filled with the mixture of graft material $(A)$ and then used to plaster the graft material on the ridge (B). Afterward the mesh is fixed with 3 screws and 1 pin (C)

(Osteoxenon ${ }^{\circledR}$ Mix Bone Granules, Bioteck, Arcugnano, Italy) in a 30:70 (autogenous:heterologous) ratio (Figs 8A and $\mathrm{B})$. The mixture was then placed on the bone defect using the mesh itself as an aid (Fig. 9A). Cover screws were placed on the implants (Fig. 9B), and the preshaped titanium mesh was secured over the defect using 3 screws and 1 pin (N1, Prodent Italia, Pero, Italy) (Fig. 9C).

The mucoperiostal flaps were tested for their ability to cover the augmented area passively. Complete flap closure was achieved using a non-resorbable suture (Monomyd 4-0/5-0 Polyamide Monofilament Suture, Butterfly, Cave- nago, Italy) (Figs 10A and B). The sutures were removed after 2 weeks, and the patient was then seen monthly.

Four months after implant placement, the antibiotic prophylaxis described above was repeated. The mesh was removed, revealing uneventful healing. The implants appeared partially submerged by newly formed bone, and the clinical appearance of the regenerated site was satisfactory (Figs 11A and B). No graft volume appeared to have been lost during the healing period. The implants were checked with a counter-torque test at $25 \mathrm{Ncm}$ and found to be stable. 

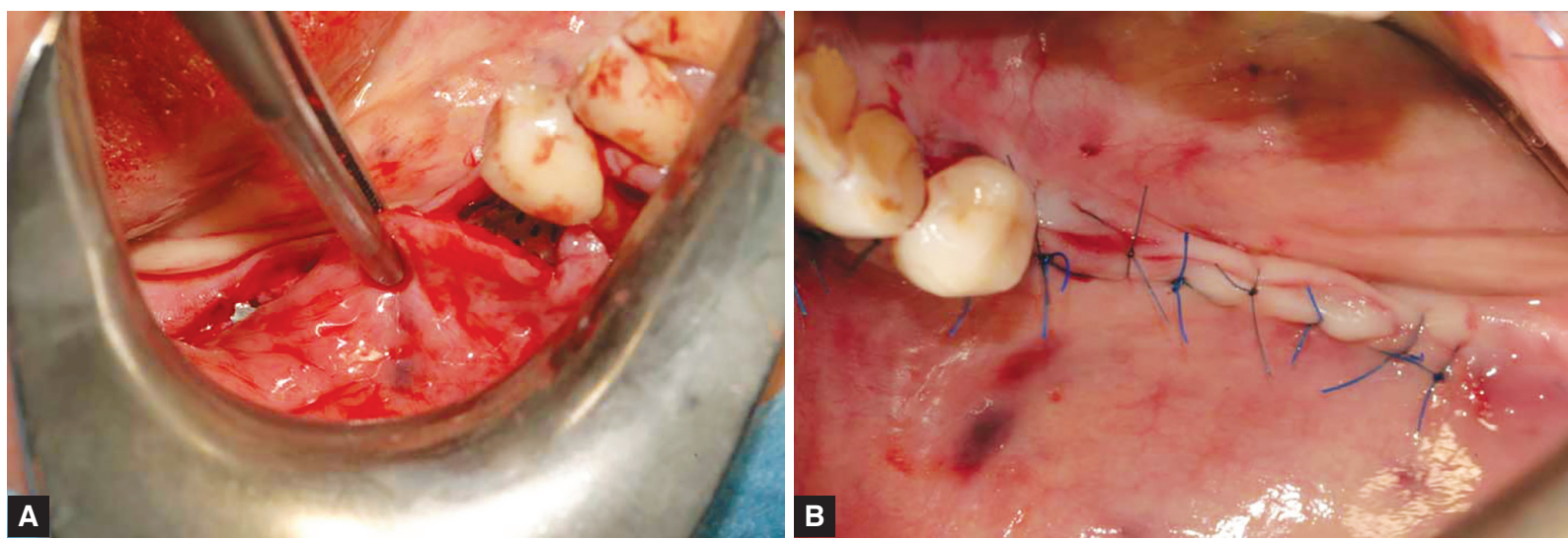

Figs $10 A$ and B: Surgical seam: after checking that the flap has been properly released $(A)$ and it is sutured (B)
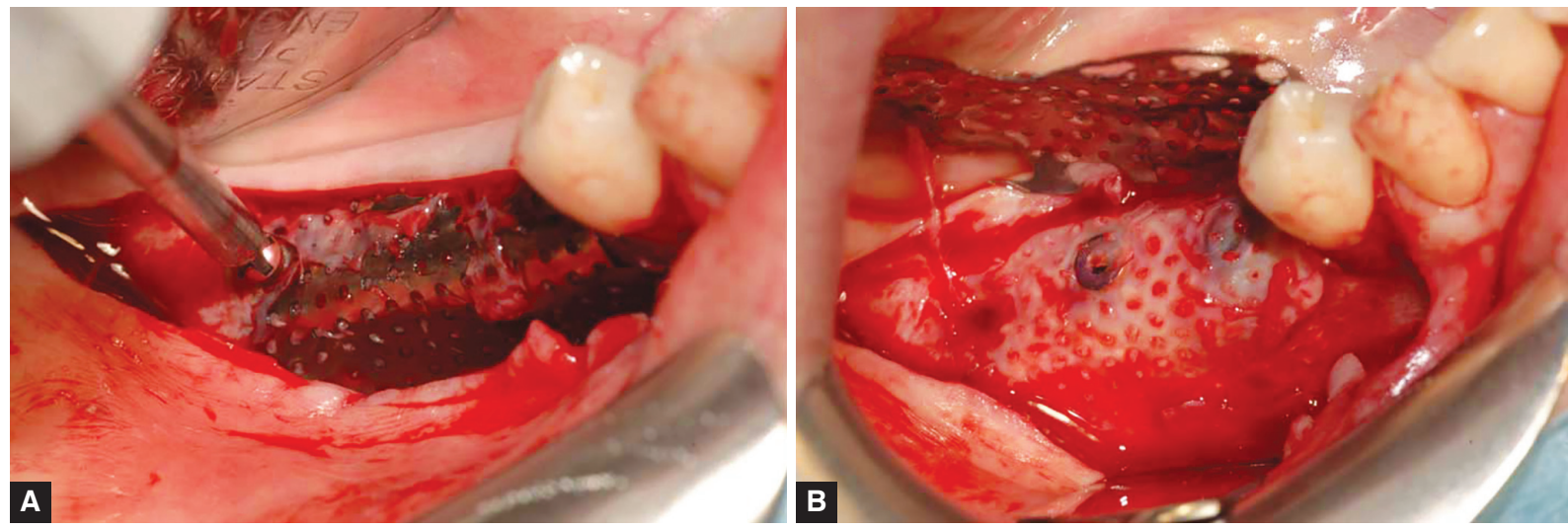

Figs 11A and B: Second surgery: the mesh is retrieved $(A)$ and the uneventful healing of the recipient site is checked (B)
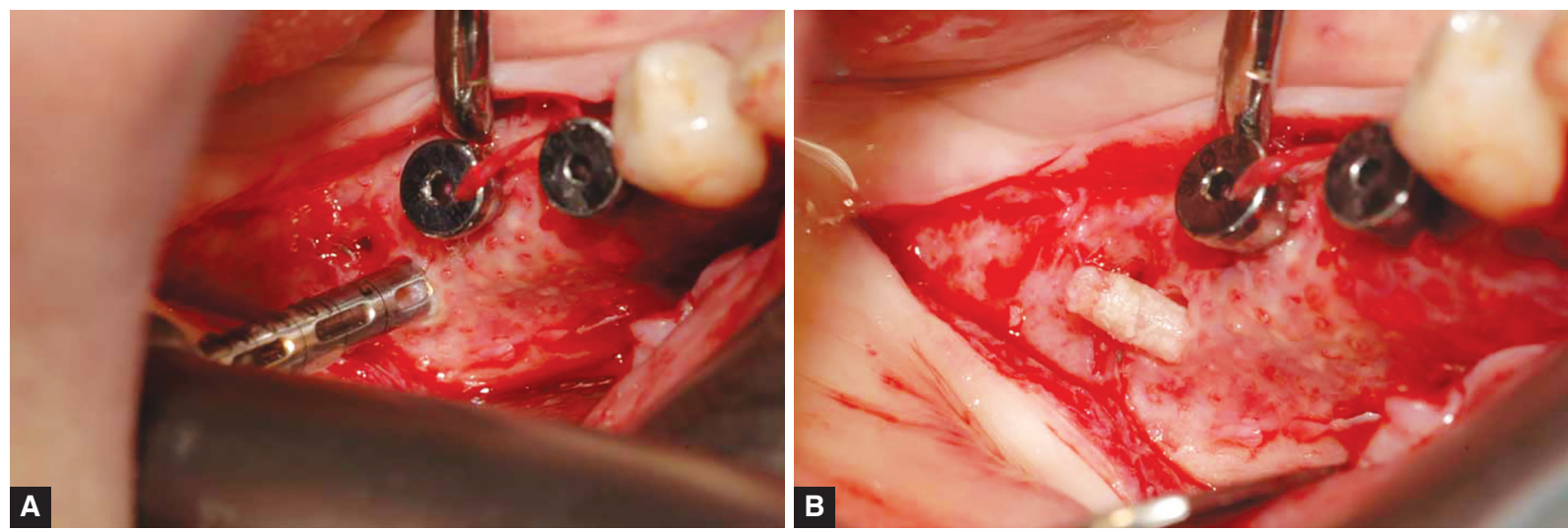

Figs 12A and B: Biopsy collection. Using a trephine (A) and a bone sample is collected (B)

A bone sample was collected on the vestibular side of the regenerated site using a $3.2 \mathrm{~mm}$ external diameter trephine (Figs 12A and B). This biopsy was fixed in $4 \%$ formalin and decalcified for 21 days in a solution containing sodium formiate $0.76 \mathrm{M}$ and formic acid $1.6 \mathrm{M}$ (Panreac Quimica, Barcelona, Spain). Subsequently, the sample was dehydrated in graded ethanol and embedded in paraffin. This procedure allowed for rapid infiltration of the tissue and the achievement of the desired softness for cutting with only minimal artifactual shrinking. It, thus, provided a tissue morphology that was representative of the in vivo bone features. Five-micron-thick sections were cut, mounted on slides, and stained with hematoxylin-eosin. Morphometric measurements were performed on the digital photomicrograph of the sample at $10 \times$ magnification, using dedicated analytic software (Image 1.33, National Institute of Health, Bethesda, USA). Measurements, performed on the whole slide, were used to calculate the ratio either of the newly formed bone or the residual biomaterial areas within the whole tissue sample. Ratios were expressed as percentages.

Histological analysis of the bone sample showed the presence of a large portion of bone tissue that could be identified as vital due to its affinity for the acid dye eosin. Vital newly formed bone and the residual graft particles were in close contact without interposing gaps. 
No inflammatory cell infiltration was observed (Fig. 13). Histomorphometric analysis provided the following measurements: newly formed bone $62.7 \%$; residual bone graft $11.1 \%$; medullary spaces $26.2 \%$.

Forty-five days after the re-entry surgery, a provisional restoration was delivered. Healing abutments and provisionally screwed crowns allowed for perfect conditioning of the soft tissue contours (Figs 14A to C). One month later, the definitive restoration was delivered, achieving final patient rehabilitation. The patient subsequently also had her upper jaw rehabilitated (Fig. 15 shows final rehabilitation of both jaws). The patient was recalled each year for the next 2 years for follow-up clinical and radiographic controls.

The intraoral control radiographs showed consistent maintenance of periimplant bone levels around both implants (Figs 16A to C). At 24 months, implants may be regarded as successful, according to Albrektsson and Zarb's criteria. Comparison of the CT scans obtained at the time of surgery and 24 months after grafting confirmed that the bone volume was being maintained overtime (Figs 16A to C).

\section{DISCUSSION}

Bone atrophy is more common in the posterior than the anterior mandible, and it has a right-left symmetric

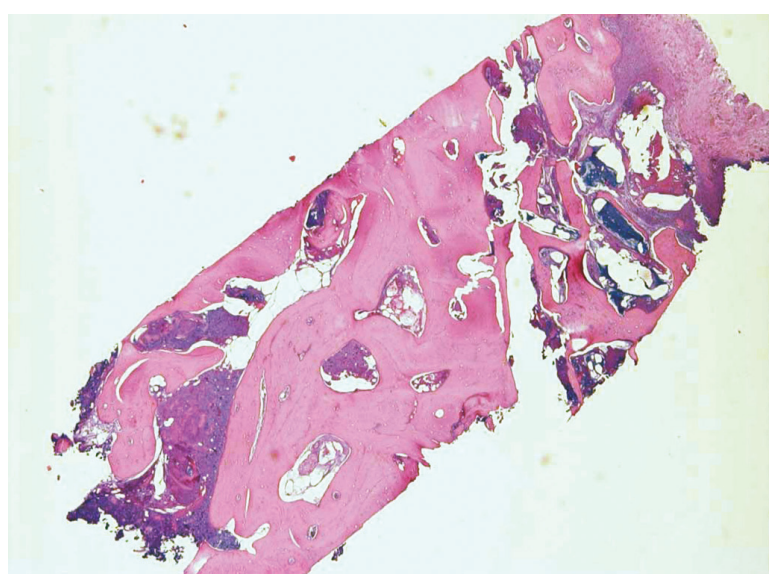

Fig. 13: Histological features of the bone sample collected 4 months after grafting and implant placement (H\&E stain at $3.5 \times$ magnification) distribution. ${ }^{53}$ Prosthetic-driven implantology calls for positioning implants in a preestablished position and direction to get the optimal functional and esthetic prosthetic result. ${ }^{54-56}$ On the other hand, severe bone defects can compromise adequate placement ${ }^{57,58}$ and make bone augmentation necessary. GBR procedures call for the use of long-lasting membranes to isolate the clot at the regenerating site and facilitate the initial bone-regenerative events, protecting the site from the invasion of cells from the surrounding soft tissues. ${ }^{4,59}$ GBR techniques show a high degree of predictability, provided proper flap closure and long-lasting protective barriers are used..$^{4-9}$ Protective barriers, moreover, must not collapse into the regenerating site, while allowing for the exchange of oxygen and nutrients between the site and the covering periosteum.

Titanium meshes fulfill the requirements of rigidity associated with a high degree of pliability. They can be easily shaped to fit the site and give the desired shape to the regenerating bone volume. Titanium meshes have been shown to provide excellent and predictable results when applied in conjunction with autogenous bone $\mathrm{e}^{13,14}$ or deproteinized bovine bone. ${ }^{12,16,17}$ Other grafting materials have been less extensively used in association with meshes. ${ }^{15}$ Equine-derived bone grafting materials have only recently been introduced into clinical practice. They show promising results provided the deantigenation treatment allows for bone collagen preservation and does not alter the remodeling kinetics of the graft, leading to new bone formation in a physiologic time span. ${ }^{44-50}$

In the present case, a mixture of equine-derived collagen-preserved material and autogenous bone provided effective bone regeneration. The histological tests showed the graft to be completely biocompatible, with no inflammatory cell infiltration and residual graft particles in contact with the newly formed bone. The extent of remodeling at 4 months was quite high (62.7\%) but in line with other reports demonstrating that the extent of regeneration, microvessel density, and expression of bone-regeneration biochemical markers were indistinguishable when autogenous bone was grafted alone or in combination with the equine-derived material. ${ }^{44}$ The
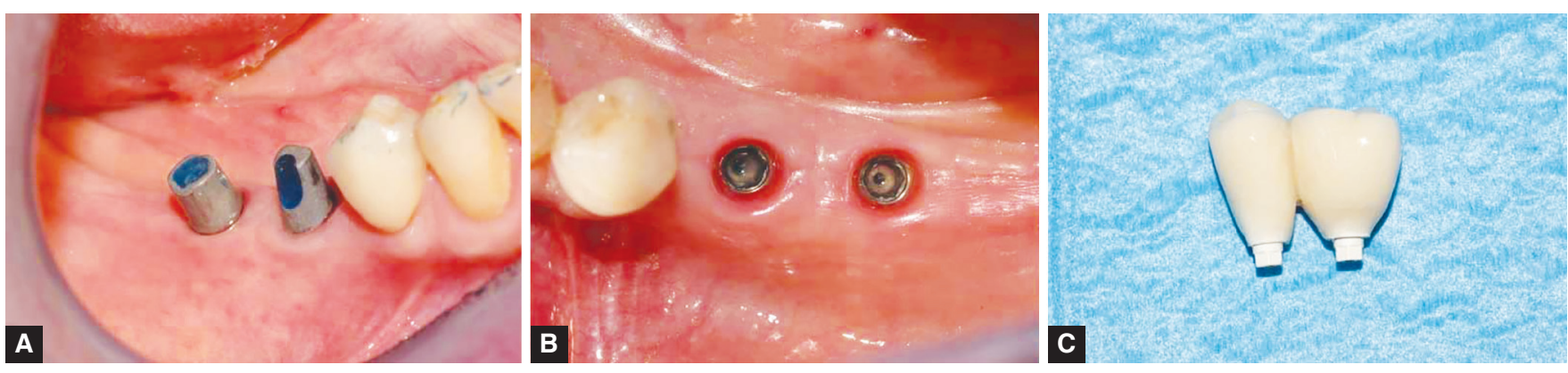

Figs 14A to C: Provisional prosthesis rehabilitation: Healing abutments $(A)$, soft tissue conditioning

(B) and the provisional crowns (C) 


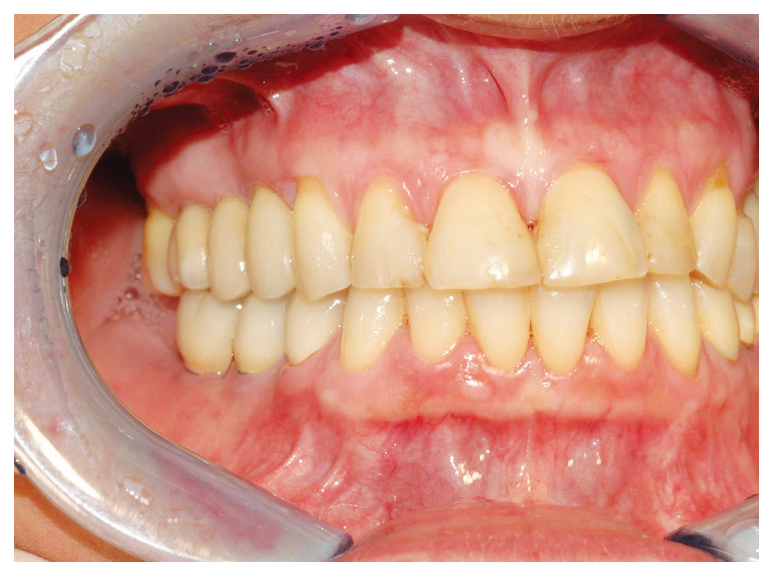

Fig. 15: The definitive crowns in position
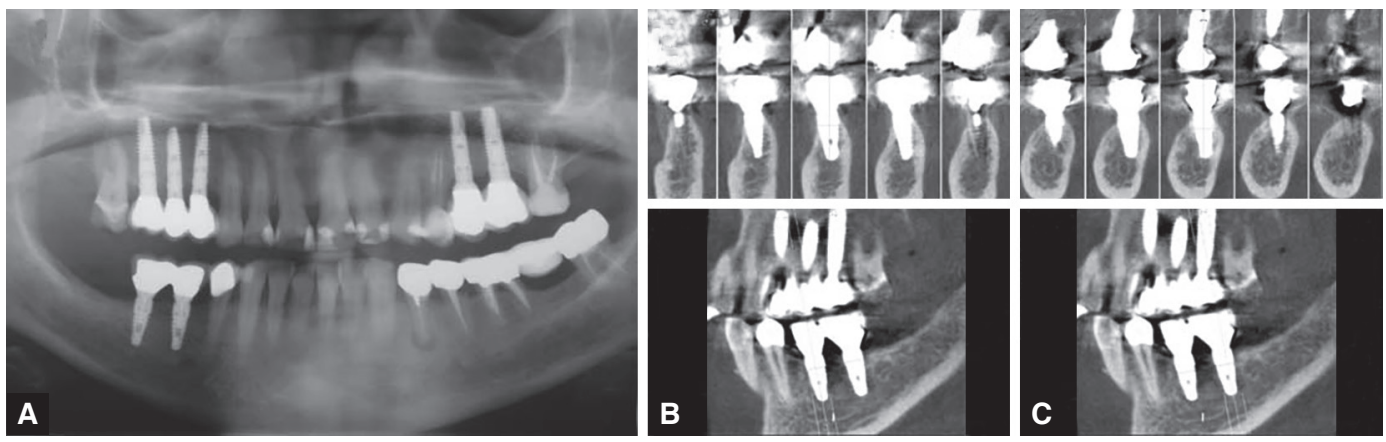

Figs 16A to C: Twenty-fourmonth follow-up. Both the panoramic radiograph (A), and CT scans at the 45

(B) and 46 position (C) display optimal periimplant bone tissue levels high extent of remodeling has been attributed to the fact that the bone collagen is preserved in its native form, facilitating the different bone-regenerative events and prompting cell adhesion and other cellular processes. ${ }^{34-41}$

The histological results correlate with the clinical findings. The regenerated bone was stable for up to and the definitive prosthetic rehabilitation.

\section{CONCLUSION}

In the present case, a preshaped titanium mesh, applied in conjunction with a heterologous, equine-derived bone graft mixed with a minor percentage of autogenous bone, provided effective bone regeneration in a GBR augmentation procedure, concomitant with the insertion of two implants in the lower right quadrant. Histological and histomorphometric analyses showed the biomaterial to be biocompatible and under advanced replacement by newly formed bone tissue at the time of sample collection (4 months after grafting). Bone levels achieved through augmentation were stable over the 24 months of follow-up. The use of a properly sized titanium mesh in conjunction with equine-derived, enzyme-deantigenic collagen-preserving bone graft provided optimal clinical and histological results. 24 months and effectively supported the two implants

\section{CLINICAL SIGNIFICANCE}

Preshaping a titanium mesh on a stereolitographic model of the patient's mandible allowed to spare the intrasurgical time usually needed to shape meshes intraoperatively, resulting in a reduced discomfort for the patient and facilitating the execution of the surgery. This practice could be, therefore, advisable in routine clinical practice.

\section{ACKNOWLEDGMENT}

The work was partially sponsored by Bioteck S.p.A. which donated the bone granules and Prodent which donated the titanium mesh. Data belonged to the authors and by no means did the manufacturers interfere with the conduct of the case or the publication of its results.

\section{REFERENCES}

1. Atwood DA. Reduction of residual ridges: a major oral disease entity. J Prosthet Dent 1971;26(3):266-279.

2. Atwood DA. Bone loss of edentulous alveolar ridges. J Periodontol 1979;50(4 Spec No):11-21.

3. Esposito M, Grusovin MG, Felice P, Karatzopoulos G, Worthington HV, Coulthard P. The efficacy of horizontal and vertical bone augmentation procedures for dental implants - a cochrane systematic review. Eur J Oral Implantol 2009;2(3):167-184.

4. Dahlin C, Linde A, Gottlow J, Nyman S. Healing of bone defects by guided tissue regeneration. Plast Reconstr Surg 1988;81(5):672-676.

5. Buser D, Brägger U, Lang NP, Nyman S. Regeneration and enlargement of jaw bone using guided tissue regeneration. Clin Oral Implants Res 1990;1(1):22-32.

6. Simion M, Scarano A, Gionso L, Piattelli A. Guided bone regeneration using resorbable and nonresorbable membranes: a comparative histologic study in humans. Int J Oral Maxillofac Implants 1996;11(6):735-742.

7. Simion M, Misitano U, Gionso L, Salvato A. Treatment of dehiscences and fenestrations around dental implants using resorbable and nonresorbable membranes associated with bone autografts: a comparative clinical study. Int J Oral Maxillofac Implants 1997;12(2):159-167. 
8. Hämmerle CHF, Jung RE. Bone augmentation by means of barrier membranes. Periodontol 2000 2003;33:36-53.

9. Bottino MC, Thomas V, Schmidt G, et al. Recent advances in the development of GTR/GBR membranes for periodontal regeneration-a materials perspective. Dent Mater Off Publ Acad Dent Mater 2012;28(7):703-721.

10. von Arx T, Hardt N, Wallkamm B. The TIME technique: A new method for localized alveolar ridge augmentation prior to placement of dental implants. Int J Oral Maxillofac Implants 1996;11(3):387-394.

11. von Arx T, Wallkamm B, Hardt N. Localized ridge augmentation using a micro titanium mesh: A report on 27 implants followed from 1 to 3 years after functional loading. Clin Oral Implants Res 1998;9(2):123-130.

12. Artzi Z, Dayan D, Alpern Y, Nemcovsky CE. Vertical ridge augmentation using xenogenic material supported by a configured titanium mesh: Clinicohistopathologic and histochemical study. Int J Oral Maxillofac Implants 2003;18(3):440-446.

13. Roccuzzo M, Ramieri G, Spada MC, Bianchi SD, Berrone S. Vertical alveolar ridge augmentation by means of a titanium mesh and autogenous bone grafts. Clin Oral Implants Res 2004;15(1):73-81.

14. Corinaldesi G, Pieri F, Marchetti C, Fini M, Aldini NN, Giardino R. Histologic and histomorphometric evaluation of alveolar ridge augmentation using bone grafts and titanium micromesh in humans. J Periodontol 2007;78(8):1477-1484.

15. Rakhmatia YD, Ayukawa Y, Furuhashi A, Koyano K. Current barrier membranes: titanium mesh and other membranes for guided bone regeneration in dental applications. J Prosthodont Res 2013;57(1):3-14.

16. Pieri F, Corinaldesi G, Fini M, Aldini NN, Giardino R, Marchetti C. Alveolar ridge augmentation with titanium mesh and a combination of autogenous bone and anorganic bovine bone: a 2-year prospective study. J Periodontol 2008; 79(11):2093-2103.

17. Proussaefs P, Lozada J, Kleinman A, Rohrer MD, McMillan PJ. The use of titanium mesh in conjunction with autogenous bone graft and inorganic bovine bone mineral (Bio-Oss) for localized alveolar ridge augmentation: a human study. Int J Periodontics Restorative Dent 2003;23(2):185-195.

18. Misch CM. Maxillary autogenous bone grafting. Oral Maxillofac Surg Clin North Am 2011;23(2):229-238.

19. Rogers GF, Greene AK. Autogenous bone graft: basic science and clinical implications. J Craniofac Surg 2012;23(1):323-327.

20. Sbordone C, Toti P, Guidetti F, Califano L, Santoro A, Sbordone L. Volume changes of iliac crest autogenous bone grafts after vertical and horizontal alveolar ridge augmentation of atrophic maxillas and mandibles: a 6-year computerized tomographic follow-up. J Oral Maxillofac Surg 2012;70(11):2559-2565.

21. Sbordone C, Toti P, Guidetti F, Califano L, Bufo P, Sbordone L. Volume changes of autogenous bone after sinus lifting and grafting procedures: a 6-year computerized tomographic follow-up. J Craniomaxillofac Surg 2013;41(3):235-241.

22. Simion M, Jovanovic SA, Trisi P, Scarano A, Piattelli A. Vertical ridge augmentation around dental implants using a membrane technique and autogenous bone or allografts in humans. Int J Periodontics Restorative Dent 1998; 18 (1): 8-23.

23. Fontana F, Santoro F, Maiorana C, Iezzi G, Piattelli A, Simion M. Clinical and histologic evaluation of allogeneic bone matrix versus autogenous bone chips associated with titanium-reinforced e-PTFE membrane for vertical ridge augmentation: a prospective pilot study. Int J Oral Maxillofac Implants 2008;23(6):1003-1012.

24. Dahlin C, Johansson A. Iliac crest autogenous bone graft versus alloplastic graft and guided bone regeneration in the reconstruction of atrophic maxillae: a 5-year retrospective study on cost-effectiveness and clinical outcome. Clin Implant Dent Relat Res 2011;13(4):305-310.

25. Schallhorn RG, Hiatt WH. Human allografts of iliac cancellous bone and marrow in periodontal osseous defects. II. Clinical observations. J Periodontol 1972;43(2):67-81.

26. Quintero G, Mellonig JT, Gambill VM, Pelleu GB Jr. A sixmonth clinical evaluation of decalcified freeze-dried bone allografts in periodontal osseous defects. J Periodontol 1982;53(12):726-730.

27. Zitzmann NU, Naef R, Schärer P. Resorbable versus nonresorbable membranes in combination with Bio-Oss for guided bone regeneration. Int J Oral Maxillofac Implants 1997;12(6):844-852.

28. Donos N, Lang NP, Karoussis IK, Bosshardt D, Tonetti M, Kostopoulos L. Effect of GBR in combination with deproteinized bovine bone mineral and/or enamel matrix proteins on the healing of critical-size defects. Clin Oral Implants Res 2004;15(1):101-111.

29. Stavropoulos A, Kostopoulos L, Nyengaard JR, Karring T. Fate of bone formed by guided tissue regeneration with or without grafting of Bio-Oss or Biogran: an experimental study in the rat. J Clin Periodontol 2004;31(1):30-39.

30. Donos N, Bosshardt D, Lang N, et al. Bone formation by enamel matrix proteins and xenografts: an experimental study in the rat ramus. Clin Oral Implants Res 2005;16(2):140-146.

31. Canullo L, Malagnino VA. Vertical ridge augmentation around implants by e-PTFE titanium-reinforced membrane and bovine bone matrix: a 24 - to 54-month study of 10 consecutive cases. Int J Oral Maxillofac Implants 2008; 23(5):858-66.

32. Zitzmann NU, Scharer $\mathrm{P}$, Marinello $\mathrm{CP}$, Schupbach $\mathrm{P}$, Berglundh T. Alveolar ridge augmentation with Bio-Oss: a histologic study in humans. Int J Periodontics Restotorative Dent 2001;21(3):288-295.

33. Benke D, Olah A, Möhler H. Protein-chemical analysis of BioOss bone substitute and evidence on its carbonate content. Biomaterials 2001;22(9):1005-1012.

34. Baslé MF, Lesourd M, Grizon F, Pascaretti C, Chappard D. Type I collagen in xenogenic bone material regulates attachment and spreading of osteoblasts over the beta1 integrin subunit. Orthopade 1998;27(2):136-142.

35. Green J, Schotland S, Stauber DJ, Kleeman CR, Clemens TL. Cell-matrix interaction in bone: type I collagen modulates signal transduction in osteoblast-like cells. Am J Physiol 1995;268(5 Pt 1):C1090-103.

36. Mizuno M, Fujisawa R, Kuboki Y. Type I collagen-induced osteoblastic differentiation of bone-marrow cells mediated by collagen-alpha2beta1 integrin interaction. J Cell Physiol 2000;184(2):207-213.

37. Liu G, Hu YY, Zhao JN, Wu SJ, Xiong Z, Lu R. Effect of type I collagen on the adhesion, proliferation, and osteoblastic gene expression of bone marrow-derived mesenchymal stem cells. Chin J Traumatol 2004;7(6):358-362.

38. Gungormus M, Kaya O. Evaluation of the effect of heterologous type I collagen on healing of bone defects. J Oral Maxillofac Surg 2002;60(5):541-545. 
39. Gungormus M. The effect on osteogenesis of type I collagen applied to experimental bone defects. Dent Traumatol 2004; 20(6):334-347.

40. Regazzoni C, Winterhalter KH, Rohrer L. Type I collagen induces expression of bone morphogenetic protein receptor type II. Biochem Biophys Res Commun 2001;283(2):316-322.

41. Toroian D, Lim JE, Price PA. The size exclusion characteristics of type I collagen: implications for the role of noncollagenous bone constituents in mineralization. J Biol Chem 2007;282(31): 22437-22447.

42. Perrotti V, Nicholls B, Piattelli A. Human osteoclast formation and activity on an equine spongy bone substitute. Clin Oral Impl Res 2009;20(1):17-23.

43. Perrotti V, Nicholls BM, Horton MA, Piattelli A. Human osteoclast formation and activity on a xenogenous bone mineral. J Biomed Mater Res A 2009;90(1):238-246.

44. Artese L, Piattelli A, Di Stefano DA, et al. Sinus lift with autologous bone alone or in addition to equine bone: an immunohistochemical study in man. Implant Dent 2011; 20(5):383-388.

45. Di Stefano DA, Artese L, Iezzi G, et al. Alveolar ridge regeneration with equine spongy bone: a clinical, histological, and immunohistochemical case series. Clin Implant Dent Relat Res 2009;11(2):90-100.

46. Di Stefano DA, Cazzaniga A, Andreasi Bassi M, Ludovichetti M, Ammirabile G, Celletti R. The use of cortical heterologous sheets for sinus lift bone grafting: a modification of Tulasne's technique with 7-year follow-up. Int J Immunopathol Pharmacol 2013;26:549-556.

47. Pistilli R, Signorini L, Pisacane A, Lizio G, Felice P. Case of severe bone atrophy of the posterior maxilla rehabilitated with blocks of equine origin bone: histological results. Implant Dent 2013;22(1):8-15.

48. Di Stefano DA, Andreasi Bassi M, Cinci L, Pieri L, Ammirabile G. Treatment of a bone defect consequent to the removal of a periapical cyst with equine bone and equine membranes: clinical and histological outcome. Minerva Stomatol 2012; 61(11-12):477-490.
49. Materni A. Managing an extreme periimplantitis. Minerva Stomatol 2013;62(9):295-305.

50. Santini S, Barbera P, Modena M, Schiavon R, Bonato M. Equine-derived bone substitutes in orthopedics and traumatology: authors' experience. Minerva Chir 2011;66(1): 63-72.

51. Cehreli M, Duyck J, De Cooman M, Puers R, Naert I. Implant design and interface force transfer. A photoelastic and strain-gauge analysis. Clin Oral Implants Res 2004;15(2): 249-257.

52. Jokstad A, Braegger U, Brunski JB, Carr AB, Naert I, Wennerberg A. Quality of dental implants. Int Dent J 2003; 53(6 Suppl 2):409-443.

53. Baljoon M, Natto S, Bergstrom J. Occurrence of vertical bone defects in dentally aware individuals. Acta Odontol Scand 2003;61(1):47-51.

54. Shanaman RH. The use of guided tissue regeneration to facilitate ideal prosthetic placement of implants. Int J Periodontics Restorative Dent 1992;12(4):256-265.

55. Baird BB. Prosthetically guided implant placement for the surgical restorative team. Dent Implantol Update 1993; $4(10): 82-84$.

56. Saadoun AP, LeGall M, Touati B. Selection and ideal tridimensional implant position for soft tissue aesthetics. Pract Periodontics Aesthetic Dent 1999;11(9):1063-1072.

57. Peñarrocha-Diago M, Gómez-Adrián MD, García-García A, Camacho-Alonso F, Rambla-Ferrer J. Vertical mandibular alveolar bone distraction and dental implant placement: a case report. J Oral Implantol 2006;32(3):137-141.

58. Urban IA, Jovanovic SA, Lozada JL. Vertical ridge augmentation using guided bone regeneration (GBR) in three clinical scenarios prior to implant placement: a retrospective study of 35 patients 12 to 72 months after loading. Int J Oral Maxillofac Implants 2009;24(3):502-510.

59. Dahlin C, Sennerby L, Lekholm U, Linde A, Nyman S. Generation of new bone around titanium implants using a membrane technique: an experimental study in rabbits. Int J Oral Maxillofac Implants 1989;4(1):19-25. 